\title{
Role of Clinical Pharmacist in Medication Management of Inotropes and Vasopressors in Intensive Care Unit
}

\author{
Sneha Sebastian', Sherine Justin', Athira PS', Lidhu Daniel², G. Sathyamurthy ${ }^{3}$, K. Menaka', \\ Sivakumar Thangavel ${ }^{4}$
}

'Department of Pharmacy Practice, Nandha College of Pharmacy, Erode, Tamil Nadu, INDIA.

${ }^{2}$ Clinical Pharmacist, Department of Clinical Pharmacy, G. Kuppuswamy Naidu Memorial Hospital, Netaji Rd, P N Palayam, Tamil Nadu, INDIA.

${ }^{3}$ Director of Operation-ICU, G. Kuppuswamy Naidu Memorial Hospital, Netaji Rd, P N Palayam, Tamil Nadu, INDIA.

${ }^{4}$ Department of Pharmaceutical Chemistry, Nandha College of Pharmacy, Erode, Tamil Nadu, INDIA.

\begin{abstract}
Background: Medication management of inotropes and vasopressors are essential in critically ill patients, as it is considered as important life-saving medications. The present study was carried out to understand the effect of these drugs on unstable patient and identifying drug-related problems like significant interactions, adverse effects, incompatibility and its factors. Methods: A prospective observational study was carried out in the medical, surgical Intensive Care Unit for a period of 6 months. All the interventions and drug related problems were categorized based on the Pharmaceutical Care Network Europe. Results: Out of 150 study population male patients were more and the majority of patients were from the age group of $60-80$ years (56.66\%). Most of the admissions were due to septic shock (50\%). Noradrenaline (64\%) were mostly prescribed. This study illustrates that there is an increased effect of drugs on hemodynamic instability based on mean arterial pressure and heart rate. By comparing before and after administration there was a significant $(P<0.0001)$ increased effect in unstable patients. Among 108 significant drug interactions, dobutamine $(50.92 \%)$ shows high in frequency. Tachycardia $(18.66 \%)$ is the most common adverse drug reactions. Among 11 incompatible combinations, Dobutamine + pantoprazole (30.18\%) shows the highest and the factors affecting the incompatibility of drugs such as diluents used, rate and duration of infusion, $\mathrm{pH}$ of drug solution. Out of 126 recommendations given by clinical pharmacist, 70 problems were solved. Conclusion: Interventions made by a clinical pharmacist improves medication safety in critically ill patients by the safe and effective use of inotropes and vasopressors.
\end{abstract}

Key words: Mean arterial pressure, Heart rate, Drug interaction, Adverse drug reaction, Incompatibility, Interventions.

\section{INTRODUCTION}

Management of medication have a crucial role to improve functional status of critically ill patient. Selection of drug, dosing, administration and monitoring strategies are day to day activities of many intensive care specialist in order to achieve targeted goal. There are chances that a trivial dose or lethal or toxic dose may result in either treatment failure or drug toxicity even though the patient receives appropriate drug. ${ }^{1}$ Therefore, there is a need for clinical pharmacist in the day to day care of the ICU patients which occurs mainly through the active participation in daily clinical visit, providing information support to the medical and nursing staff; analysing and monitoring the effectiveness of pharmacotherapy; and preventing, identifying and reporting adverse reactions. There are several prospective controlled trials which reveals remarkable low level of occurrence in ADEs and lesser days of hospital stay when a clinical pharmacist plays a vital role with intensive care healthcare team. The drug-related problems evaluated in the study are ADR, DI and Y-site incompatibilities. Incompatibility describes preventable or reversible precipitation or insolubility. Y-site incompatibility arises
DOI: 10.5530/ijopp.13.2.21

Address for correspondence: Dr.Sneha Sebastian

Pharm D graduate, Department of Pharmacy Practice, Nandha College of Pharmacy, Erode, Tamil Nadu, INDIA.

Phone no: +91-08921630968 Email Id: snehakadumathil@ gmail.com

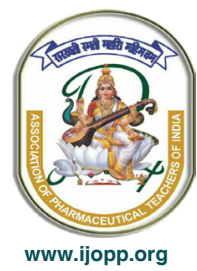


when two or more medications are administered via the Y-site connector mix in the lumen of the tubing before being infused into the patient. Co-administration of incompatible medications include central venous catheter occlusion and precipitation, ultimately leads to reduced potency of medication, therapeutic failure and local and systemic inflammatory reactions.

Inotropes and vasopressors are the most important life-saving medications, they can even be considered as holistic medicines, which are originated from various pharmacological groups and act at some of the central receptor and signal transduction systems in the body. Inotropes are agents administered to increase contractility of heart muscles whereas vasopressor agents are administered to increase constriction of blood vessels. ${ }^{2}$ These potent agents is greatly beneficial to seriously ill patients "with profound hemodynamic impairment such that tissue blood flow is not sufficient to meet metabolic requirements". Vasopressors improves adequate MAP, while inotropes produces appropriate effect on oxygen delivery. ${ }^{3}$ The effects of the inotropes and vasopressors mainly studied are dobutamine, dopamine, adrenaline, noradrenaline, vasopressin and levosimendan. Inotropes and vasopressors are regularly injected to ill patients in critical phase to surpass hemodynamic function and reinstate adequate organ perfusion. ${ }^{4}$ Pharmaceutical interventions related to DRPs were classified based on PCNE Classification (V8.02). It classifies DRPs into four different levels, problems, cause, intervention and outcome.

\section{MATERIALS AND METHODS}

\section{Study design and setting}

The prospective observational study was carried out in the medical and surgical ICU at G. Kuppusamy Naidu Memorial Hospital, Coimbatore, Tamil Nadu, which is a 583 bedded super specialty hospital. The study was mainly conducted over a period of 6 months from February 2018 to July 2018. The ICUs included in the study consist of 30 beds. All the interventions and drug related problems were grouped based on the Pharmaceutical Care Network Europe (PCNE V8.02) and were entered in the DRP registration form.

Data were collected using a well-structured data collection form which included patient demographics, haemodynamic parameters such as BP, MAP, HR, were collected from the ICU chart, laboratory parameters and the medication chart. Patient data were collected by the clinical pharmacist on daily from the patient case files. The effect of inotropes and vasopressors in the hemodynamic instability in ICU patients and DRPs like interaction,
ADR, incompatibility of inotropes and vasopressors with other drugs were analysed. All the discrepancies observed have been documented appropriately and pharmaceutical care has been implemented by finding drug interactions, ADRs, incompatibilities and DIs were informed to the health care professionals. ADRs were analyzed by the using Naranjo causality assessment scale. A simple questionnaire was developed and distributed to nurses to collect data regarding the occurrence of IV incompatibilities in the Y-site administration of drugs.

\section{Subjects}

The observational study used a prospective audit of 150 patients who were admitted to the medical and surgical ICUs and who were on inotropes and vasopressors. All cases of the patients above the age of 18 who were admitted in ICUs and were on inotropes and vasopressors were included. Patients who refused to participate and patients below the age of 18 were excluded from the study.

\section{Data analysis}

The data collected were analysed statistically by using SPSS software version 19.

\section{RESULTS}

A total of 150 patients cases were collected during the study period of 6 months. Patient demographics show that the males [103 (68.66\%)] were predominant than females [47(31.33\%)] and the mean age of patients was $60.32 \pm 19.739$ (range: 18 to 89 ) as showed in [Table 1].

Table 2 shows that the majority of the admissions were due to septic shock [75(50\%)] followed by cardiogenic shock [50(33.33\%)]. Heart failure [12(8\%)] and the remaining $[13(8.66 \%)]$ patients were due to other disease conditions like endocrine disorders and neurologic disorders. While analyzing the pattern of utilization of inotropes and vasopressors it was found that the most commonly prescribed were noradrenaline [96(64\%)]. Followed by dobutamine [60(40\%)], dopamine [39(26\%)]. Vasopressin [20(13.33\%)], adrenaline [19(12.66\%)] and levosimendan $[3(2 \%)]$ accounts for remaining population.

Figure 1 illustrates that there is an increased effect of inotropes and vasopressors on hemodynamic instability based on mean arterial pressure and heart rate. A total of 16 stable and 134 unstable patients were found before administration. The number of increased stable [94(62.66\%)] and unstable [56(37.34\%)] after administration according to MAP and according to HR it was found that, after administration of drugs 
led to increase in number of stable $[114(76 \%)]$ and unstable [36(24\%)] patients. By comparing before and after administration based on MAP and HR, significant $(p<0.0001)$ increase in the effect of inotropes and vasopressors were found in unstable patients.

Table 3 shows that the identified drug related problem with inotropes and vasopressors. Among 108 significant drug-drug interactions, dobutamine [55(50.92\%)] shows high in frequency, followed by noradrenaline [21(19.44\%)], vasopressin [13(12.037\%)], dopamine [7(6.48\%)], levosimendan [7(6.48\%)] and adrenaline [5(4.62\%)]. Most of the potential drug interactions were significant (major and moderate) than serious and contraindicated. Tachycardia [28(18.66\%)] is the most common ADR identified followed by bradycardia [10(6.66\%)], cardiac arrest $[10(6.66 \%)]$, tachyarrythmiasis $[9(6 \%)]$ and dyspnoea [5(3.33\%)]. Most of the reactions were definite when assessed with Naranjo causality assessment scale. Incidence of Y-site drug incompatibility calculates about 53 that includes 11 incomapatible combinations. Dobutamine + pantoprazole [16(30.18\%)], dobutamine + furosemide $[7(13.0 \%]$ showed highest usage among the continous IV drug along with Y-site drugs and were found to be incompatible. Noradrenaline+sodiumbicarbonate [6(11.32\%)], dopamine+sodiumbicarbonate [4(7.54\%)], noradrenalin+furosemide $[4(7.54 \%)]$, dobutamine +insulinregular [3(5.66\%)], adrenaline+sodiumbicarbonate [2(3.77\%)] vasopressin+sodiumbicarbonate [2(3.77\%)], dobutamine + sodiumbicarbonate $[2(3.77 \%)]$, noradrenaline + insulinregular $[2(3.77 \%)]$, adrenaline + sodiumbicarbonate $[2(3.77 \%)]$ are the identified incompatible combinations.

Table 4 point out the factors affecting the incompatibility of drugs such as the diluents used, rate of infusion, duration of infusion, $\mathrm{pH}$ of drug solution. Most of the drug pairs were found to have different $\mathrm{pH}$ values ranging from 2.5(acidic) to 11(basic).

Figure 2 illustrates the 2-dimensional Y-site drug incompatibility alert chart. This chart indicates the compatibility of inotropes and vasopressors (continuous IV infusions) with Y-site administered drugs commonly used in ICU.

Table 5 shows the classification of pharmaceutical interventions related to DRPs based on PCNE Classification (V8.02). It classifies DRPs into four different levels, problems, cause, intervention and outcome.

126 DRPs were observed in this study and the majority of the issues were due to treatment safety $[70(55.55 \%)]$ and secondly by treatment effectiveness [56(44.44\%)]. Moreover, from the various causes, dose selection [13(38.23\%)] followed by drug selection [10(29.44\%)] results in DRPs. Recommendations made by the pharmacist were mostly at drug level [10(62.5\%)] followed by prescriber level [6(37.5\%)]. 4 intervention were accepted from the recommendation. Out of 126 DRPs identified, $70(55.55 \%)$ problems were successfully solved.

\section{DISCUSSION}

A seriously ill patient treated and analysed by physicians from various specialties, hence polypharmacy is an usual practice in the hospital setting. The study aims to understand the effect of inotropes and vasopressors on unstable patients and identify its drug related problems like significant interactions, adverse effects, incompatibility and its factors.

In this study, 150 patient's cases were collected during

\section{Table 1: Demographic details ( $n=150)$.}

Characteristics Frequency Percentage (\%)

\begin{tabular}{ccc}
\hline Age in years & $60.32 \pm 19.739$ & \\
$18-384$ & $2.66 \%$ & $32.66 \%$ \\
$39-59$ & 49 & $56.66 \%$ \\
$60-80$ & 85 & $8 \%$ \\
$>80$ & 12 & \\
Gender & & $68.66 \%$ \\
Male & 103 & $31.33 \%$ \\
Female & 47 & \\
\hline
\end{tabular}

Table 2: Pattern of disease and utilization of inotropes and vasopressors $(n=150)$.

Characteristics

Frequency

Percentage (\%)

Diagnosis for inotropes and vasopressors

Septic shock

75

$50 \%$

Cardiogenic shock

50

failure

12

$33.33 \%$ Heart

Others

13

$8 \%$

$8.66 \%$

Pattern of utilization of inotropes and vasopressors

$\begin{array}{ccc}\text { Noradrenaline } & 96 & 64 \% \\ \text { Dobutamine } & 60 & 40 \% \\ \text { Dopamine } & 39 & 26 \% \\ \text { Adrenaline } & 19 & 12.66 \% \\ \text { Vasopressin } & 20 & 13.33 \% \\ \text { Levosimendan } & 3 & 2 \%\end{array}$

Indian Journal of Pharmacy Practice, Vol 13, Issue 2, Apr-Jun, 2020 
Table 3: Drug-related problems identified with Inotropes and vasopressors.

\begin{tabular}{|c|c|c|c|}
\hline \multicolumn{4}{|c|}{ Drug interaction } \\
\hline Drugs & $\begin{array}{l}\text { No. of significant drug } \\
\text { interactions }(n=108)\end{array}$ & & Percentage (\%) \\
\hline Noradrenaline & 21 & & $19.44 \%$ \\
\hline Dobutamine & 55 & & $50.92 \%$ \\
\hline Dopamine & 7 & & $6.48 \%$ \\
\hline Adrenaline & 5 & & $4.62 \%$ \\
\hline Vasopressin & 13 & & $12.037 \%$ \\
\hline Levosimendan & 7 & & $6.48 \%$ \\
\hline Adverse drug reactions & No. of patients $(n=150)$ & & Percentage (\%) \\
\hline Tachycardia & 28 & & $18.66 \%$ \\
\hline Bradycardia & 10 & & $6.66 \%$ \\
\hline Cardiac arrest & 10 & & $6.66 \%$ \\
\hline Tachyarrythmiasis & 9 & & $6 \%$ \\
\hline Dyspnoea & 5 & & $3.33 \%$ \\
\hline \multicolumn{4}{|l|}{ Incompatibility } \\
\hline Drugs & $\begin{array}{c}\text { Y-site administered } \\
\text { drug }\end{array}$ & frequency $(n=53)$ & Percentage (\%) \\
\hline \multirow[t]{3}{*}{ Noradrenaline } & Insulin regular & 2 & $3.77 \%$ \\
\hline & Furosemide & 4 & $7.54 \%$ \\
\hline & Sodium bicarbonate & 6 & $11.32 \%$ \\
\hline \multirow[t]{4}{*}{ Dobutamine } & Insulin regular & 3 & $5.66 \%$ \\
\hline & Pantoprazole & 16 & $30.18 \%$ \\
\hline & Furosemide & 7 & $13.20 \%$ \\
\hline & Sodium bicarbonate & 2 & $3.77 \%$ \\
\hline Dopamine & Sodium bicarbonate & 4 & $7.54 \%$ \\
\hline Adrenaline & Sodium bicarbonate & 2 & $3.77 \%$ \\
\hline \multirow[t]{2}{*}{ Vasopressin } & Insulin regular & 4 & $7.54 \%$ \\
\hline & Sodium bicarbonate & 3 & $5.66 \%$ \\
\hline
\end{tabular}

6 months out of which 103 males and 47 females were found. The male patient was predominant when compared with a female population in Indian ICU settings shown by a study conducted by A. Vijaykumar et al. ${ }^{5}$ The mean age of patients were $60.32 \pm 19.739$ (range: 18 to 89 ) and less number of patients under the age group 18-38.

The present study carried out in MICU and CCU, majority of the admissions on inotropes and vasopressors were due to septic shock [75(50\%)] followed by cardiogenic shock [50(33.33\%)]. The findings were similar to the study conducted by Jacob C. Jentzer et al. ${ }^{6}$ It was found that most commonly prescribed inotropes and vasopressors were noradrenaline [96(64\%)]. Noradrenaline is the preferred first line vasopressor agent associated with lower rates of $\mathrm{ADE}$ and decreased the mortality rate and therefore increased use for patients with septic shock. This result was similar to the study done by Sacha Pollard et al. ${ }^{7}$ Followed by dobutamine [60(40\%)], dopamine [39(26\%)] showed that dobutamine were predominant followed by dopamine according to the hospital patterns of use of positive inotropic agents in patients with heart failure. This is supported by Chohreh Patrovian et al. ${ }^{8}$

This study illustrates the increased effect of inotropes and vasopressors on hemodynamic instability based on mean arterial pressure and heart rate and the data are analyzed by using SPSS statistics 19 .

A total of 16 stable and 134 unstable patients were found before administration. There is an increased number in stable [94(62.66\%)] and unstable [56(37.34\%)] patients after administration based on MAP and according to HR it was found that, after administration of drugs led to increase in number of stable [114(76\%)] and unstable [36(24\%)] patients. By comparing before and after administration based on MAP and HR significant $(p<0.0001)$ increase in the effect of inotropes and vasopressors were found in unstable patients. This will be helped in improving hemodynamic function and to restore adequate organ perfusion and thereby decreases 
Table 4: Details of factors affecting incompatibility of drugs.

Drugs and dilution Y-site drug rate of infusion duration $\mathrm{pH}$ of Y-site drug $\mathrm{pH}$ of drug

\begin{tabular}{|c|c|c|c|c|c|}
\hline $\begin{array}{c}\text { Noradrenaline (8mg) } \\
+\end{array}$ & Insulin regular & $8 \mathrm{ml} / \mathrm{h}$ & $24 \mathrm{~h}$ & $7-7.8$ & $3-4.0$ \\
\hline \multirow[t]{2}{*}{$50 \mathrm{ml} \mathrm{NS}$} & Furosemide (20mg) & $8 \mathrm{ml} / \mathrm{h}$ & $24 \mathrm{~h}$ & $8-9.3$ & $3-4.0$ \\
\hline & Sodium bicarbonate & $15 \mathrm{ml} / \mathrm{h}$ & $24 \mathrm{~h}$ & $7-8.5$ & $3-4.0$ \\
\hline $\begin{array}{c}\text { Dobutamine(250mg) } \\
+\end{array}$ & Pantoprazole (40mg) & $2 \mathrm{ml} / \mathrm{h}$ & $24 \mathrm{~h}$ & $8-9.3$ & $2.5-5.5$ \\
\hline \multirow[t]{3}{*}{$50 \mathrm{ml} \mathrm{NS}$} & Insulin regular & $1.5 \mathrm{ml} / \mathrm{h}$ & $24 \mathrm{~h}$ & $7-7.8$ & $2.5-5.5$ \\
\hline & Sodium bicarbonate & $1.5 \mathrm{ml} / \mathrm{h}$ & $24 \mathrm{~h}$ & $7-8.5$ & $2.5-5.5$ \\
\hline & Furosemide (20mg) & $2 \mathrm{ml} / \mathrm{h}$ & $24 \mathrm{~h}$ & $8-9.3$ & $2.5-5.5$ \\
\hline $\begin{array}{c}\text { Dopamine (400mg) } \\
+ \\
40 \mathrm{ml} \mathrm{NS}\end{array}$ & Sodium bicarbonate & $4 \mathrm{ml} / \mathrm{h}$ & $24 \mathrm{~h}$ & $7-8.5$ & $2.5-4.5$ \\
\hline $\begin{array}{c}\text { Adrenaline (8mg) } \\
+ \\
50 \mathrm{ml} \mathrm{NS}\end{array}$ & Sodium bicarbonate & $10 \mathrm{ml} / \mathrm{h}$ & $24 \mathrm{~h}$ & $7-8.5$ & $2.2-5.0$ \\
\hline Vasopressin (40IU) & Insulin regular & $2.4 \mathrm{ml} / \mathrm{h}$ & $24 \mathrm{~h}$ & $7-7.8$ & $3.8-5.2$ \\
\hline+ & Sodium bicarbonate & $2.4 \mathrm{ml} / \mathrm{h}$ & $24 \mathrm{~h}$ & $7-8.5$ & $3.8-5.2$ \\
\hline $50 \mathrm{ml} \mathrm{NS}$ & & & & & \\
\hline
\end{tabular}

the mortality rate. This was supported in the study done by A. Belletti et al. ${ }^{4}$

Significant drug-drug interaction, adverse drug reaction, Y-site incompatibility and its factors are the identified drug related problems with inotropes and vasopressors.

Among 108 significant drug interactions, dobutamine [55(50.92\%)] shows high in frequency due to the complexity of pharmacotherapies administered and ultimately led to adverse effects shown in the study done by Yulis Hamidy. M et al. ${ }^{9}$ Most of the potential drug interactions were significant (major and moderate) than serious and contraindicated.

Inotropes and vasopressors are associated with adverse reactions, mainly includes cardiovascular effects. Tachycardia [28(18.66\%)] is the most common ADR identified followed by bradycardia [10(6.66\%)], cardiac arrest $[10(6.66 \%)]$, tachyarrythmiasis $[9(6 \%)]$ and dyspnoea [5(3.33\%)] and it was supported on the review by Steven M. Hollenberg ${ }^{10}$ and Brad E. Cooper. ${ }^{3}$ All the ADRs were reported to CDSCO using suspected ADR reporting form. Most of reactions were definite when assessed with the Naranjo causality assessment scale.

The preparation and administration of IV drugs are associated with considerable risk and one of the most important is physicochemical incompatibilities. As a result of this, the drug loses its efficacy or precipitates. Clinical pharmacist may not prevent but can reduce the incidence of such incompatibilities, which occurs due to the lack of knowledge of nursing staff regarding the

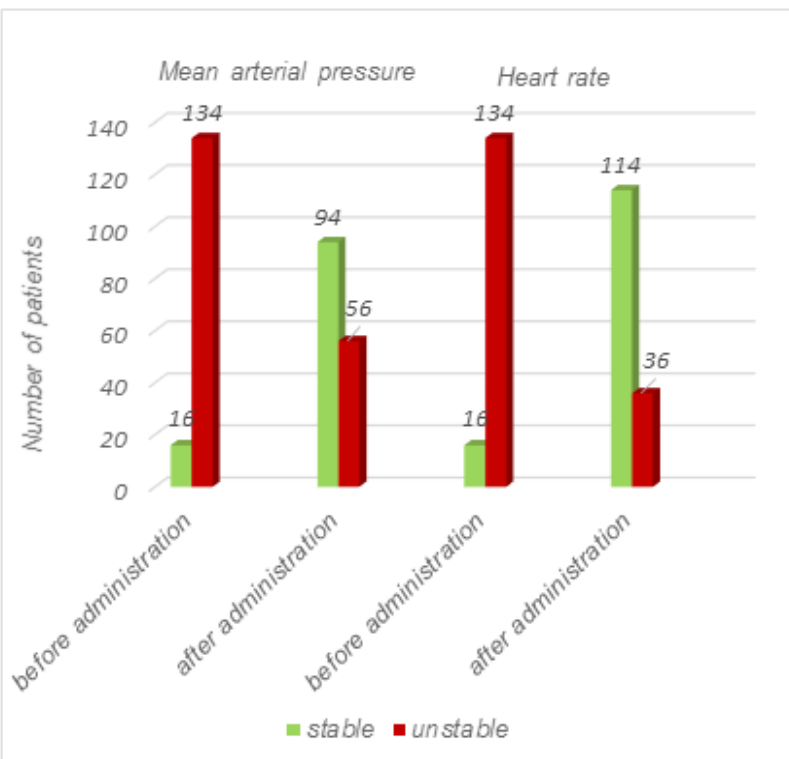

Figure 1: Effect of inotropes and vasopressors on hemodynamic instability based on mean arterial pressure and heart rate $(n=150)$.

*The level of statistical significance was at $P<0.0001$ ( $95 \%$ significance)

Indian Journal of Pharmacy Practice, Vol 13, Issue 2, Apr-Jun, 2020 


\begin{tabular}{|c|c|c|c|}
\hline Code V8.02 & & Primary Domains & \\
\hline Problems & & Number of problems & Total\% \\
\hline $\mathrm{P} 1$ & Treatment effectiveness & 56 & $44.44 \%$ \\
\hline \multirow[t]{3}{*}{ P2 } & Treatment safety & 70 & $55.55 \%$ \\
\hline & TOTAL & 126 & \\
\hline & Causes & Number of causes & Total\% \\
\hline $\mathrm{C} 1$ & Drug selection & 10 & $29.44 \%$ \\
\hline C3 & Dose selection & 13 & $38.23 \%$ \\
\hline $\mathrm{C} 4$ & Treatment duration & 5 & $14.70 \%$ \\
\hline \multirow[t]{3}{*}{$\mathrm{C} 6$} & Drug use & 6 & $17.64 \%$ \\
\hline & TOTAL & 34 & \\
\hline & Planned interventions & $\begin{array}{l}\text { Number of } \\
\text { recommendations }\end{array}$ & Total\% \\
\hline 11 & At prescriber level & 6 & $37.5 \%$ \\
\hline \multirow[t]{2}{*}{13} & At drug level & 10 & $62.5 \%$ \\
\hline & TOTAL & 16 & \\
\hline $\mathrm{A} 1$ & Intervention accepted & 4 & $25 \%$ \\
\hline \multirow[t]{3}{*}{ A2 } & Intervention not accepted & 12 & $75 \%$ \\
\hline & TOTAL & 16 & \\
\hline & Status of DRP & $\begin{array}{c}\text { Number of problem } \\
\text { solved }\end{array}$ & Total\% \\
\hline 01 & Problem solved & 70 & $55.55 \%$ \\
\hline \multirow[t]{2}{*}{03} & Problem not solved & 56 & $44.4 \%$ \\
\hline & TOTAL & & 126 \\
\hline
\end{tabular}

compatibilities of drugs.

We have documented 53 Y-site drug incompatibility that includes 11 incompatible combinations. Dobutamine+pantoprazole [16(30.18\%)], dobutamine+furosemide [7(13.02\%)] showed higher usage among the continuous IV drug along with Y-site drugs and were found to be incompatible in our study. On the other way incompatibility between dobutamine+furosemide could be related to the fact that the combination of mildly alkaline (furosemide) and acidic solution (dobutamine) resulted in instability to the final mixture. This incompatible drug combinations were also reported by a study carried out by Heleena. ${ }^{11}$ Factors affecting these incompatibilities are due to the diluents used, rate of infusion, duration of infusion, $\mathrm{pH}$ of drug solution. Most of the drug pairs were found to have different $\mathrm{pH}$ values ranging from 2.5 (acidic) to 11(basic) and most of the inotropes and vasopressors had a $\mathrm{pH}$ value in acidic ranges while that of Y-site administered drugs were found to be in the alkaline range. Similar results had shown in studies conducted by Heleena ${ }^{11}$ and A. Vijayakumar $e t$ al. ${ }^{5}$

The 2-dimensional Y-site drug incompatibility alert card was prepared to enhance the rational use of IV medications and patient safety. This chart indicates the compatibility of inotropes and vasopressors (continuous IV infusions) with Y-site administered drugs commonly used in ICU.

Finally, all the pharmaceutical interventions related to DRPs were classified based on PCNE Classification (V8.02). It classifies DRPs into four different levels, problems, cause, intervention and outcome.

126 DRPs were observed in this study and the majority of the issues of treatment safety [70(55.55\%)] were due to adverse drug reaction occurred and secondly by treatment effectiveness [56(44.44\%)] due to lack of effect in pharmacotherapy by drug interactions and incompatibility. These findings were similar to one observed in study done by Muhammad Umair Khan et al. ${ }^{12}$ Moreover from the various causes, dose selection [13(38.23\%)] followed by drug selection [10(29.44\%)] results in DRPs. Recommendations made by the pharmacist were mostly at drug level $[10(62.5 \%)]$ followed by the prescriber level [6(37.5\%)]. Similarly observed in the study done by Mohamed Hisham et al. ${ }^{1} 4$ intervention were accepted from the recommendation. Out of 126 


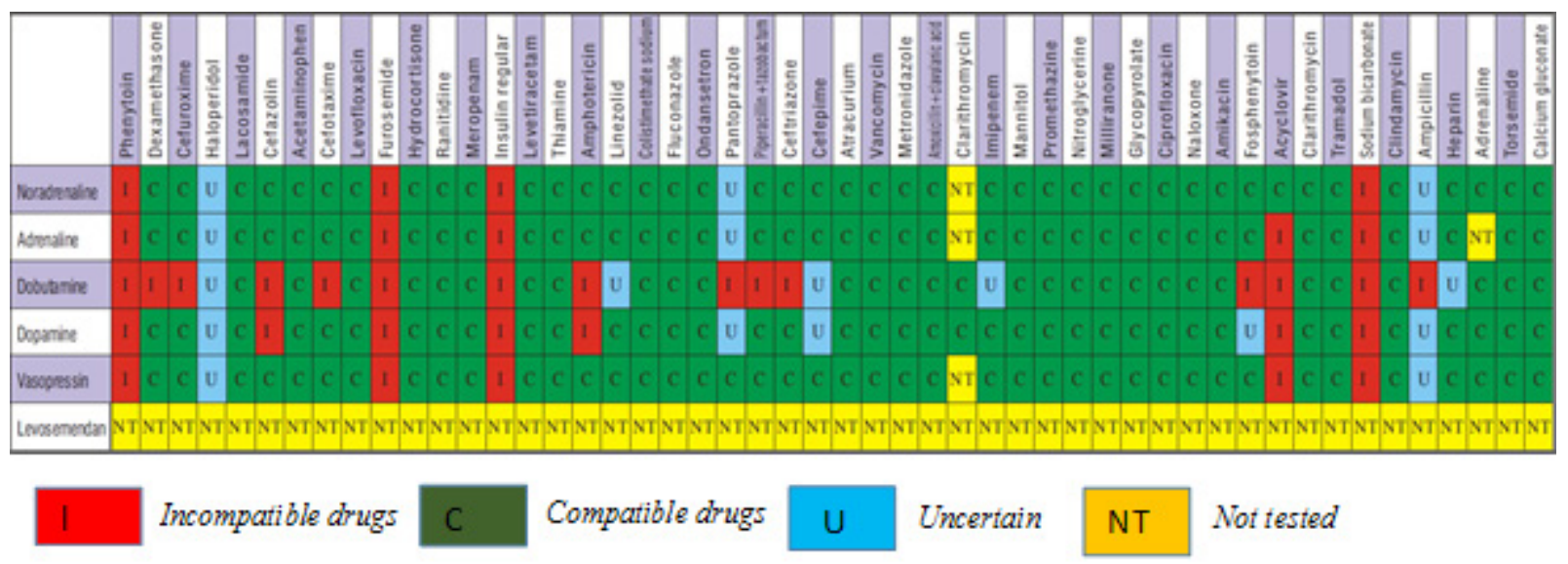

Figure 2: 2-dimensional Y-site drug compatibility chart.

DRPs identified, $70(55.55 \%)$ problems were successfully solved.

\section{CONCLUSION}

The study concludes that interventions made by a clinical pharmacist improves medication safety in critical care units thereby lowering the rates of adverse drug events caused by drug incompatibilities and drug interactions and enhances the effect of inotropes and vasopressors on haemodynamic unstable patients. Through our study, we found out 108 significant drug interactions, 5 major ADRs and 11 incompatible combinations. The PCNE classification system, especially revised DRP category was found to be very useful, which helps to classify the DRPs in an effective manner.

\section{ACKNOWLEDGEMENT}

We thank GKNM HOSPITAL for permitting us to assess all required medical resources database, we would like to show our gratitude to K. Menaka, M.Pharm., Assistant Professor at Nandha College of Pharmacy and Dr. Lidhu Daniel, clinical pharmacist at GKNM Hospital for their valuable feedback and constant encouragement.

\section{Ethical consideration}

The ethical approval to conduct the study was obtained from the Ethical Review Committee of G. Kuppuswamy Naidu Memorial Hospital. Written consents were obtained from each participant's bystander.

\section{CONFLICT OF INTEREST}

The authors declare no conflict of interest.

\section{ABBREVIATIONS}

CCU: Critical care unit; MICU: Medical intensive care unit; ICU: Intensive care unit; ADE: Adverse drug events; ADR: Adverse drug reaction; DI: Drug interaction; CDSCO: Central drug standard control organization; DRP: Drug related problem; MAP: Mean arterial pressure; HR: Heart rate; BP: Blood pressure; IV: Intravenous; NS: Normal saline; $\mathbf{p H}$ : Power of hydrogen; SPSS: Statistical Package for the Social Sciences; PCNE: Pharmaceutical Care Network Europe.

\section{REFERENCES}

1. Mohamed H, Mundalipalayam NS, Ganesh V. Impact of clinical pharmacist in an Indian intensive care unit. Indian Journal of Critical Care Medicine. 2016;20(2):78-83.

2. Tarvasmäki T, Lassus J, Varpula M, Sionis A, Sund R, Kober L, et al. Current reallife use of vasopressors and inotropes in cardiogenic shock-adrenaline use is associated with excess organ injury and mortality. Critical Care. 2016;20(1):208.

3. Cooper BE. Review and update on inotropes and vasopressors. AACN Advanced Critical Care. 2008;19(1):5.

4. Belletti A, Castro ML, Silvetti S, Greco T, Biondi-Zoccai G, Pasin L, et al. The effect of inotropes and vasopressors on mortality: A meta-analysis of randomized clinical trials. BJA: British Journal of Anaesthesia. 2015;115(5):656-75.

5. Vijayakumar A, Sharon EV, Teena J, Nobil S, Nazeer I. A clinical study on drugrelated problems associated with intravenous drug administration. Journal of Basic and Clinical Pharmacy. 2014;5(2):49.

6. Jentzer JC, Coons JC, Link CB, Schmidhofer M. Pharmacotherapy update on the use of vasopressors and inotropes in the intensive care unit. Journal of Cardiovascular Pharmacology and Therapeutics. 2015;20(3):249-60.

7. Pollard S, Edwin SB, Alaniz C. Vasopressor and inotropic management of patients with septic shock. Pharmacy and Therapeutics. 2015;40(7):438.

8. Chohreh P, Scott RG, Purav SM, Shu XL, Haiyan W, Kelly MS, et al. Hospital patterns of use of positive inotropic agents in patients with heart failure. Journal of the American College of Cardiology. 2012;60(15):1402-9.

9. Hamidy YM, Fauzia DI. Significant drug interactions among intensive care unit patients. Asian Journal of Pharmaceutical and Clinical Research. 2017;35-8.

10. Hollenberg SM. Inotrope and vasopressor therapy of septic shock. Critical Care Nursing Clinics. 2011;23(1):127-48.

11. Heleena MT. Effect of $\mathrm{pH}$ and Polyvalent Cations on the Y-site Incompatibility of Continuous Intravenous Infusions of Selected Critical Care Drugs in the Medical Intensive Care Unit. (Doctoral dissertation, College of Pharmacy, Sri Ramakrishna Institute of Paramedical Sciences, Coimbatore). 2016;1-64.

12. Khan MU, Ahmad A. The impact of clinical pharmacists' interventions on drug related problems in a teaching-based hospital. Int J Pharm Clin Res. 2014;63(63):276-80.

Indian Journal of Pharmacy Practice, Vol 13, Issue 2, Apr-Jun, 2020 